\title{
Restitución de los restos mortales encontrados en el cerro Yanquenao, provincia de Chubut
}

\author{
María M. Frère* y Ana M. Aguerre*
}

\section{Resumen}

En la presente nota se da a conocer una experiencia de trabajo surgida a partir del pedido de la restitución de restos mortales de la comunidad tehuelche-mapuche de la localidad de Sarmiento, provincia de Chubut. Estos restos habían sido hallados en 1979 en el Cerro Yanquenao, al norte del lago Colhue Huapi, por Carlos J. Gradín. Desde entonces estuvieron conservados en el Instituto de Arqueología de la Facultad de Filosofía y Letras de la Universidad de Buenos Aires (UBA). Aquí se describen los pasos seguidos en el proceso de la restitución, en el cual intervinieron, además de miembros de la comunidad y del Instituto, las autoridades del Programa Nacional de Identificación y Restitución de Restos Humanos Indígenas del Instituto Nacional de Asuntos Indígenas (INAI) y de la Facultad de Filosofía y Letras de la UBA. Esta experiencia contribuyó, una vez más, a la reflexión acerca de nuestras prácticas profesionales como arqueólogos y de la necesidad de instalar nuevas formas de diálogo y de interacción entre académicos, instituciones, autoridades estatales y comunidades originarias.

\section{Restitution of the mortal remains found at Cerro Yanquenao, province of Chubut}

\begin{abstract}
This brief article analyzes a work experience that emerged from the request for the restitution of mortal remains by the Tehuelche-Mapuche community of Sarmiento, Chubut Province. These remains were found in 1979 at Cerro Yanquenao, north of the Colhue Huapi Lake, by Carlos J. Gradin. Since then, they have been preserved in the Institute of Archaeology of the Facultad de Filosofía y Letras, Universidad de Buenos Aires (School of Philosophy and Literature of the University of Buenos Aires). Here, we describe the steps followed in the restitution process, with special emphasis on the intervention of the authorities of the National Program of Identification and Restitution of Indigenous Human Remains of the National Institute of Indigenous Affairs (INAI) and of the Facultad de Filosofía y Letras as well as of the members of the community and the Institute. This experience contributed, once again, to think about our professional practice as archaeologists and the need to adopt new forms of dialogue and interaction between academic, institutions, state authorities, and aboriginal communities.
\end{abstract}

\footnotetext{
* Instituto de Arqueología, Facultad de Filosofía y Letras, Universidad de Buenos Aires (UBA), 25 de mayo 217, $3^{\circ}$ piso (CP C1002ABE) Ciudad Autónoma de Buenos Aires, Argentina. E-mail: magdafrere@gmail.com; amaguerre@ gmail.com
}

Recibido:

26 de marzo de 2019

Aceptado:

2 de julio de 2019

Palabras clave

Restitución

Comunidad tehuelche-mapuche Práctica profesional

Keywords

Restitution

Tehuelche-mapuche community Professional practice 


\section{Introducción}

En este artículo se presenta a la comunidad académica científica una experiencia de trabajo entre el Instituto de Arqueología (IA) de la Facultad de Filosofía y Letras de la Universidad de Buenos Aires, el Instituto Nacional de Asuntos Indígenas (INAI) y la comunidad indígena mapuche-tehuelche de la localidad de Sarmiento en la provincia de Chubut. Esta comunidad solicitó al INAI la restitución de los restos mortales que habían sido hallados en 1979 en el Cerro Yanquenao por Carlos J. Gradín. Estos restos óseos se encontraban en el Instituto de Arqueología, en tenencia temporaria para facilitar las investigaciones y los análisis correspondientes. Cabe aclarar que estos restos humanos no formaban parte de las colecciones permanentes del IA. En la actualidad, a partir de la sanción de la Ley Nacional 25.743, los investigadores de las diferentes instituciones y universidades deben contar con la autorización de los organismos competentes para la tenencia temporaria de los materiales culturales provenientes de los trabajos de investigación arqueológica. Luego de completar los estudios pertinentes que nuestra disciplina requiere, los materiales se devuelven a la provincia o a los museos provinciales que correspondan.

\section{Algunos casos de reclamos de los pueblos originarios por la restitución de los restos mortales}

Los reclamos de los pueblos originarios por la restitución de los restos óseos de sus antepasados tienen sus antecedentes en Argentina en la década de 1980 y años después se iniciaron amplios debates en el ámbito académico (Guraieb y Frère, 2012; Lazzari, 2011; Pupio y Salerno, 2014). En la esfera internacional, un momento importante fue la firma del Acuerdo de Vermillion de 1989 en el cual arqueólogos y comunidades indígenas compatibilizaron criterios para el tratamiento de los restos humanos. $\mathrm{Al}$ año siguiente, el Congreso norteamericano sancionó el Acta de Protección y Repatriación de Sepulcros de Nativos Americanos (NAGPRA, Native American Graves Protection and Repatriation Act), lo que ayudó a otorgar visibilidad al tema de las restituciones.

En Argentina, tuvieron lugar dos casos emblemáticos de restitución de restos humanos indígenas: los del cacique tehuelche Inakayal y los del cacique ranquel Panguitruz Nürü, ambos en el Museo de La Plata (Endere, 2000, 2011, 2013; Endere y Curtoni, 2006). Posteriormente, sobre todo a partir de la promulgación de la Ley Nacional 25.517 del año 2001, aumentaron los reclamos de restitución con diferentes grados de controversia (ver diferentes casos en Corpus, Archivos virtuales de la alteridad americana 2011, Dossier sobre reclamos y restituciones de restos humanos).

En los últimos años, se restituyeron numerosos restos esqueletarios a distintas comunidades originarias. Así, en abril de 2013 el Centro Nacional Patagónico (CENPAT) entregó restos de 13 individuos a la comunidad originaria mapuchetehuelche Ceferino Namuncurá-Valentín Sayhueque de Gaiman, provincia de Chubut (Cholila Online, 2014; Gómez Otero, 2011). Otro caso fue el de los restos mortales de la esposa de Inakayal y su sobrina, Margarita Foyel, en el 2014, los cuales se encontraban en el Museo de Ciencia Naturales de La Plata. También en el año 2016 se restituyeron los restos óseos de integrantes de la comunidad Selknam y de caciques mapuche-tehuelche. Durante el año 2017 se entregaron restos mortales pertenecientes a la comunidad Peña Mapu y a la Comunidad Catriel y en el año 2018 se restituyeron restos humanos de indígenas Qom ("Política de restitución de restos humanos", 2018). Cada una de estas restituciones se realizó en contextos particulares y tienen un significado diferente para cada uno de los actores involucrados, ya sea para la comunidad originaria que realizó el reclamo como para las instituciones estatales nacionales, provinciales o municipales. 
Este recorrido de las restituciones surgió con los reclamos indígenas de nuestro país al reconocimiento legal de la propiedad de las tierras ancestralmente ocupadas y al derecho a su identidad y a su propia cultura, lo que estimuló debates sobre la necesidad de atender estas demandas. De este modo, surgió una agenda con nuevos temas en la arqueología, se organizaron diferentes reuniones con especialistas y se emitieron diversos documentos y declaraciones. A modo de ejemplo, podemos mencionar a la Declaración de Río Cuarto en el 2005 en el marco del Primer Foro Arqueólogos-Pueblos originarios, el Código de ética de la AAPRA (Asociación de Arqueólogos Profesionales de la República Argentina) aprobado en el 2010 y el Código Deontológico de la Asociación Argentina de Antropología Biológica redactado en el 2011. Se organizaron cuatro Talleres de Discusión sobre Restitución de Restos Humanos de Interés Arqueológico y Bioantropológico. En estos talleres se debatió sobre las implicancias éticas y profesionales de la aplicación de la Ley 25.517 y su Decreto Reglamentario 701/10. Al mismo tiempo, se acordaron lineamientos generales y orientaciones en relación con el tratamiento ético de restos humanos y su restitución y se advirtió la necesidad de contar con el consentimiento previo, libre e informado de las comunidades indígenas para su investigación científica.

\section{Normativa en el tratamiento de los restos humanos de valor arqueológico o bioantropológico}

Existen numerosos trabajos que versan sobre el marco normativo internacional y nacional respecto a las comunidades originarias (Endere, 2000, 2013; Endere y Ayala, 2012; Endere y Rolandi, 2007; Guraieb y Frère, 2012; entre otros). En esta nota queremos señalar algunas normas legales internacionales y nacionales que fueron hitos importantes para respaldar los reclamos de las poblaciones originarias, particularmente en el tratamiento de los restos humanos de valor arqueológico o bioantropológico.

El tema de la cultura y la identidad indígena fue considerado en el Convenio 107 de la Organización Internacional del Trabajo (OIT) en 1957. Más tarde, en el Convenio 169 de la OIT (1989), Convenio sobre pueblos indígenas y tribales en países independientes, se amplía el reconocimiento de los derechos culturales. En el año 1992, la Ley Nacional $\mathrm{N}^{\circ} 24.071$ ratificó el Convenio 169 de la OIT. Esta ley establece que los gobiernos deberán tomar las medidas que sean necesarias para garantizar la protección efectiva de los derechos de propiedad y posesión de las tierras ocupadas tradicionalmente por los pueblos indígenas. No obstante, el instrumento de ratificación no se logró hasta el año 2000 que tomó jerarquía constitucional (Endere, 2013).

En 1985 se sanciona la Ley Nacional No 23.302 de Política Indígena y apoyo a las Comunidades Aborígenes que reconoce el estatus legal de las comunidades indígenas. Además, a partir de esta ley se creó el Instituto Nacional de Asuntos Indígenas (INAI), cuyo funcionamiento se hizo efectivo luego de la reglamentación de la ley en 1989.

Conjuntamente, la Reforma de la Constitución Nacional de 1994, en su artículo 75, inciso 17, reconoce la preexistencia étnica y cultural de los pueblos indígenas, garantiza los derechos a su identidad, a una educación bilingüe e intercultural, a la posesión y propiedad de las tierras que tradicionalmente ocupan, como también a la personería jurídica de sus comunidades y a la participación en la gestión de sus recursos naturales y de todo otro tema que los afecte.

En 2007, la Asamblea General de la Organización de las Naciones Unidas (ONU) aprueba la Declaración sobre los derechos de los pueblos indígenas. En su artículo primero menciona que tienen derecho, como pueblos o como individuos, al disfrute pleno de todos los derechos humanos y las libertades fundamentales reconocidas en 
la Carta de las Naciones Unidas, la Declaración Universal de Derechos Humanos y las normas internacionales de derechos humanos. Si bien esta Declaración no tiene el estatus jurídico de una Convención, implica un compromiso de los estados miembros de la Organización de las Naciones Unidas.

Finalmente, en el año 2001 fue sancionada la Ley Nacional $N^{\circ} 25.517$ que consta de cinco artículos y en el primero establece que los restos mortales de aborígenes deberán ser puestos a disposición de las comunidades indígenas de pertenencia que los reclamen. Mientras que aquellos que no sean reclamados podrán seguir a disposición de las instituciones que los albergan, debiendo ser tratados con el respeto y consideración que merecen (Artículo 2). Esta ley establece también que para realizarse todo emprendimiento científico que tenga por objeto a las comunidades aborígenes, incluyendo su patrimonio histórico y cultural, deberá contarse con el expreso consentimiento de las comunidades interesadas (Artículo 3).

En el año 2010 se dictó el Decreto 701, referido a la Ley Nacional Nº 25.517 con el objetivo de hacer efectivo su articulado. Mediante este decreto el INAI tiene a cargo, entre otras acciones, la realización de los relevamientos necesarios para identificar los restos mortales de aborígenes que formen parte de museos y/o colecciones públicas o privadas. Esto implica, participar en las solicitudes de restitución de restos mortales provenientes de las comunidades y/o pueblos indígenas y expedir los antecedentes históricos, étnicos, culturales y biológicos que se conformen ante cada reclamo.

\section{Información acerca de los restos humanos procedentes del cerro Yanquenao}

El cerro Yanquenao está ubicado a $85 \mathrm{~km}$ de la localidad Sarmiento, al norte del lago Colhue Huapi en la provincia de Chubut. En 1979, Carlos J. Gradín junto con su equipo encontró un enterramiento tipo chenque, es decir, una acumulación artificial de rocas. La forma del mismo era oval y sus medidas eran aproximadamente de 1,90 por 1,20 m.

Carlos J. Gradín, especialista reconocido en el arte rupestre patagónico con proyección internacional, pertenecía al Instituto de Antropología de la Facultad de Filosofía y Letras de la UBA con sede en el Museo Etnográfico. En 1970 inició los trabajos arqueológicos en la provincia de Chubut con apoyo del CONICET (Consejo Nacional de Investigaciones Científicas y Técnicas) y de la Dirección de Cultura del Chubut. El equipo estaba conformado por Carlos Aschero y Ana Margarita Aguerre, además de colaboradores alumnos de la Facultad de Filosofía y Letras de la UBA y del Instituto de Historia de la Universidad de Trelew. Posteriormente, en 1972, el equipo amplió su área de trabajo de investigación al noroeste de la provincia de Santa Cruz, con centro en Perito Moreno (Río Pinturas) donde se encuentra Cueva de las Manos y, de este modo, comenzó a desarrollar una investigación regional. En el marco de este proyecto, Gradín se hizo cargo de los trabajos en el Cerro Yanquenao, además de otros importantes sitios en el Chubut, como los del Alero de las Manos Pintadas en el paraje de las Pulgas, así como el del Cerro Shequen cerca de la localidad de Facundo (Gradín, 2001).

El hallazgo del entierro de Cerro Yanquenao se produjo cuando Gradín se hallaba revisando nuevamente el sitio con grabados rupestres. Durante su excavación se recuperaron los restos de un individuo adulto cuyo esqueleto mostraba un alto grado de articulación y de integridad. La sepultura carecía de ajuar funerario y no estaba asociada a otros materiales arqueológicos. Los restos humanos fueron llevados al Instituto de Ciencias Antropológicas (no existía el Instituto de Arqueología como tal) y desde entonces estuvieron conservados en los depósitos de la Facultad de Filosofía y Letras de la UBA. La profesora en Antropología Física, Josefa Patti de Martínez Soler, 
con la colaboración de la Lic. Teresa A. López, ambas pertenecientes al Instituto de Antropología de la Facultad, tuvieron a su cargo el estudio del esqueleto. El Gobierno del Chubut publicó en 1989 dichos trabajos (Gradín, 1989).

En el año 2003, la Dra. Ana Margarita Aguerre y equipo, con apoyo del proyecto PIPCONICET 02466/2004, retoman los estudios en el sur de Chubut y emprenden la realización de nuevos análisis del esqueleto del cerro Yanquenao. En el 2009, los Dres. Solana García Guraieb, Valeria Bernal, Paula N. González, Luis A. Bosio y Ana Margarita Aguerre, realizan estas investigaciones con la aplicación de nuevas metodologías y técnicas analíticas y publican los estudios realizados (García Guraieb, Bernal, González, Bosio y Aguerre, 2009; García Guraieb, Bosio y Pereyra, 2015). Así, se determinó que los restos pertenecían a un individuo de sexo masculino con una edad de entre 40 y 50 años al momento de su muerte. Presentaba una deformación craneana de tipo tabular erecto, variedad plano-frontal que es común en Pampa y Patagonia. La estatura del individuo no difiere en ambos estudios, llegando a 1,66 m. El fechado radiocarbónico indicó una antigüedad de $1151 \pm 59$ años AP (AA 71849). Además, se realizaron análisis de isótopos estables y un estudio paleopatológico que evidenció la presencia de lesiones propias de la treponematosis, estando aún en proceso un estudio de ADN antiguo.

\section{Gestiones realizadas para la restitución}

El Programa Nacional de Identificación y Restitución de Restos Humanos Indígenas del INAI envió su primera nota en agosto de 2017 (cuando todavía el Dr. Guillermo Mengoni Goñalons era director del IA) en la que consultaban si en el Instituto se encontraban los restos mortales hallados en el cerro Yanquenao. A partir de allí, hubo un intercambio de correspondencia en el cual se informó que los restos óseos allí exhumados se encontraban en el Instituto, acondicionados y bien conservados.

En abril de 2018, el Dr. Nicolás Torres, Director de la Dirección de Afirmación de los Derechos Indígenas del INAI nos informó que el Señor Raúl Mera, representante de la comunidad del Linaje Yanquenao, solicitaba la restitución del esqueleto a través del señor Julio Vera Ortíz, mandatario de los reclamantes ante la mencionada Dirección. En notas posteriores, comunicaron la recepción de diferentes apoyos al pedido de restitución: el Sr. Ricardo Rubén Saihueque, Director de Asuntos IndígenasSubsecretaría de Relaciones Institucionales del Ministerio de Coordinación de Gabinete de la provincia del Chubut, de familiares descendientes del linaje Yanquenao y miembros de la comunidad tehuelche-mapuche Yanquenao, de la señora Margarita Santibáñez, lonko de la comunidad Tehuelche "El Chalia" (Departamento Senguer, Chubut) y del señor Anastasio Antileo, Consejero de Participación Indígena (CPI) de la provincia de Chubut. Paralelamente a estas notas de apoyo, el Programa Nacional de Identificación y Restitución de Restos Humanos Indígenas del INAI realizaba análisis y consultas correspondientes a esta solicitud de restitución.

Desde el primer momento, el Instituto de Arqueología y los investigadores responsables de los restos mortales manifestaron la buena voluntad y el deseo de restituir los mismos a la comunidad tehuelche de Yanquenao. Las autoridades de la Facultad desde la Secretaría de Investigación y la Sra. Decana, Dra. Graciela Morgade, estaban informadas de este reclamo como de los avances en las negociaciones y, por lo tanto, comprometidas con el cumplimiento de los requisitos para la restitución definitiva de los restos humanos solicitados. De este modo, cumplíamos también con lo establecido en el artículo 1 de la Ley $\mathrm{N}^{\circ}$ 25.517: "Los restos mortales de aborígenes, cualquiera fuera su característica étnica, que formen parte de museos y/o colecciones públicas o privadas, deberán ser puestos a disposición de los pueblos indígenas y/o comunidades de pertenencia que lo reclamen". 
El 18 de julio de 2018, se llevó a cabo una reunión en el Instituto de Arqueología donde participaron el Sr. Julio Vera Ortíz, mandatario de la comunidad tehuelche Yanquenao junto con el Lic. Fernando Pepe del Programa Nacional de Identificación y Restitución de Restos Humanos Indígenas del INAI. Además, estuvieron presentes las Dras. Ana Margarita Aguerre (investigadora del IA), M. Magdalena Frère (secretaria Académica del IA a cargo de la dirección del instituto), el Dr. Guillermo Mengoni Goñalons (investigador del IA), la Sra. Norma Pérez (encargada del área de Conservación del IA) y la Mag. Laura Staropoli (Secretaria Administrativa del IA). En este encuentro se entregaron al señor Vera las últimas publicaciones acerca de los estudios realizados sobre los restos óseos del cerro Yanquenao, además, la constancia del retiro de muestras del esqueleto para realizar el estudio de ADN que ya había sido autorizado por los reclamantes. Antes de finalizar la reunión, los participantes visitaron el laboratorio de Conservación donde se pudo observar los restos óseos en perfecto estado.

Con posterioridad, se inició el expediente administrativo en la Facultad de Filosofía y Letras en el mes de agosto de 2018. A partir de esto, el Dr. Bosco, consultor legal de la Facultad y el Lic. Pepe, acordaron definir los requisitos legales y administrativos necesarios para completar la gestión. Finalmente, el 17 de agosto de 2018, el INAI informó que no hubo otro pedido registrado sobre estos restos mortales y evaluó positivamente la posibilidad de realizar la restitución a los reclamantes. Por lo tanto, como dice el informe técnico que nos enviaron en septiembre de 2018, se sugirió al Instituto de Arqueología la entrega de los restos en referencia al Sr. Raúl Mera o, en su defecto, a su representante para estas diligencias, el Sr. Julio Vera Ortiz.

En un acto público realizado el 11 de octubre del 2018, se firmó el Acta de Restitución y se procedió a la entrega de los restos exhumados en el Cerro Yanquenao ante la presencia, entre otros, de los Sres. Julio Cesar Vera y Raúl Mera, de la comunidad tehuelchemapuche Yanquenao, el Dr. Nicolás Torres del INAI, el rector de la Universidad de Buenos Aires, Dr. Alberto E. Barbieri, la decana de la Facultad de Filosofía y Letras, Dra. Graciela Morgade, y el Secretario de Investigación, Dr. Marcelo Campagno.

Los restos mortales fueron llevados en avión por los representantes de la comunidad y fueron enterrados nuevamente en el Cerro Yanquenao el día 12 de octubre que, como explicaron sus descendientes, “...volver con los restos al territorio donde está toda su descendencia es permitir que el hermano que llevamos de regreso lo abrace la madre tierra y pueda completar su ciclo" ("Restituyeron los restos del hombre de cerro Yanquenao", 2018).

Cabe aclarar que la restitución se realizó a través del INAI, en cumplimiento de la Ley Nacional $N^{\circ} 25.517$ y su Decreto Reglamentario 701/10 que establece que el INAI, organismo de aplicación, será el encargado de coordinar, articular y asistir en el seguimiento y estudio del cumplimiento de las directivas y acciones dispuestas por la mencionada ley nacional. Es importante mencionar que la provincia de Chubut adhirió a esta normativa a través de la Ley Provincial V 159. Además la provincia fue notificada y adhirió en su nombre el Director de Asuntos Indígenas-Subsecretaría de Relaciones Institucionales del Ministerio de Coordinación de Gabinete, Rubén Saihueque. Finalmente, el Instituto de Arqueología de la Facultad de Filosofía y Letras de la Universidad de Buenos Aires, organismo nacional, entregó un informe acerca de la gestión realizada al Instituto Nacional de Antropología y Pensamiento Latinoamericano (INAPL), organismo de aplicación nacional de la Ley $\mathrm{N}^{\circ} 25.743$.

\section{Comentarios finales}

La restitución de los restos mortales encontrados en el cerro Yanquenao realizada el 11 de octubre del 2018 constituyó un acontecimiento inédito para el IA porque era la primera 
vez que tenía lugar un hecho de estas características. Cabe mencionar nuevamente que estos restos humanos no formaban parte de sus colecciones permanentes sino que se encontraban bajo la tenencia temporaria de investigadores con la dirección de la Dra. Ana Margarita Aguerre.

Como vimos, durante los últimos años las normativas legales han cambiado sustancialmente aunque todavía resultan insuficientes. Por otra parte, los arqueólogos hemos realizado, y lo seguimos haciendo, una reflexión sobre nuestras prácticas y nuestra ética profesional. A lo largo de la historia de nuestra disciplina, hemos tenido que modificar modos de trabajo y dar lugar a voces que están igualmente involucradas e interesadas en los restos mortales indígenas y en la cultura material del pasado. Estas voces representan actores sociales que deben ser incluidos y no olvidados, pues, como ya mencionamos, muchas de estas demandas indígenas de restitución están orientadas, al mismo tiempo, a la recuperación de territorios ancestrales y al fortalecimiento de su identidad.

Nuestros colegas del área de Antropología Social también se han replanteado el enfoque etnográfico centrado en el interés exclusivo de los investigadores para tomar en consideración las iniciativas y demandas de pueblos y comunidades indígenas. Se instaló así una línea de trabajo antropológico a través de la gestión participativa y etnografía colaborativa (Briones, 2018; Briones y Ramos, 2010; Carrasco, 2018; Lazzari, Rodríguez y Papazian, 2015; Rodríguez, 2011; Rodríguez y Alaniz, 2018, entre otros).

En el caso de la experiencia de restitución de los restos mortales exhumados en el Cerro Yanquenao es posible aseverar que se realizó sobre la base de la confianza mutua, el respeto por el reclamo legítimo de la comunidad Yanquenao en relación con los restos de sus ancestros y por el interés, también legítimo, del conocimiento científico. En este intercambio prevalecieron la responsabilidad, la escucha y el compromiso en el diálogo respetuoso.

Pensamos que con esta nueva mirada en el abordaje del trabajo arqueológico contribuimos también en la formación de los jóvenes profesionales y estudiantes. Ellos deberán actuar en un escenario donde el patrimonio cultural, en muchos casos, es objeto de reclamos, por lo que las decisiones que se toman al respecto no pueden quedar libradas solo al criterio del profesional sino que deben considerar, del mismo modo, el de otros agentes sociales interesados.

Finalmente, sabemos que los lugares de entierro son sitios sagrados que señalan ocupaciones de largo tiempo y que los ancestros inhumados tienen injerencia sobre las esferas de la vida y la muerte de las poblaciones indígenas. Así, la carta de Margarita Santibañez, lonko del Lof El Chalia, departamento Senguer del Chubut, enviada al INAI en mayo de 2018 expresa: “... es de vital importancia y desde nuestra cosmovisión el regreso de nuestro peñi (hermano) al territorio, para así recuperar la armonía perdida por la profanación de su tumba...". A través de esta nota queremos trasmitir una experiencia de aprendizaje donde se evidenció que en el ejercicio de nuestra profesión de producir conocimiento científico son claves la participación, el diálogo y el respeto por los derechos indígenas.

\section{Agradecimientos}

Al Lic. Fernando Pepe del Instituto Nacional de Asuntos Indígenas (INAI), a la directora del Instituto Nacional de Antropología y Pensamiento Latinoamericano, Lic. Leonor Acuña, a las autoridades del Registro Nacional de Yacimientos, Colecciones y Objetos Arqueológicos (RENYCOA), quienes nos asesoraron en los diferentes momentos de esta restitución y nos acompañaron en este importante acontecimiento. A Carlos Gradín (h) y María Onetto por la revisión del resumen en inglés. A los evaluadores y al Comité Editorial de la revista Arqueología por el tiempo dedicado a la lectura y evaluación de la presente nota. 


\section{Referencias citadas}

" Briones, C. (2018). Los caminos de la Teoría desde la colaboración y el compromiso. En M. Carrasco (Ed.), Campos de interlocución y políticas del reconocimiento indígena en la Argentina (pp. 7-11). Buenos Aires: Antropofagia.

" Briones, C. y Ramos, A. (2010). Replanteos teóricos sobre las acciones indígenas de reivindicación y protesta: aprendizajes desde las prácticas de reclamo y organización mapuche-tehuelche en Chubut. En G. Gordillo y S. Hirsch (Eds.), Movilizaciones indígenas e identidades en disputa en la Argentina (pp. 39-78). Buenos Aires: La Crujía-Flacso.

" Carrasco, M. (2018). Introducción. En M. Carrasco (Ed.), Campos de interlocución y políticas del reconocimiento indígena en la Argentina (pp.13-17). Buenos Aires: Antropofagia.

»Cholila Online [CholilaOnline]. (2014, 8 de agosto). Somos Chubut Documental Loma Torta [Archivo de video]. Recuperado de: https://www.youtube.com/watch?v=2a8c3oe]dPA

»Endere, M. L. (2000). Patrimonios en disputa: acervos nacionales, investigación arqueológica y reclamos étnicos sobre restos humanos. Trabajos de Prehistoria, 57(1), 1-13.

"Endere, M. L. (2011). Cacique Inakayal. La primera restitución de restos humanos ordenada por ley. Corpus. Archivos virtuales de la alteridad americana 1(1), http://ppct. caicyt.gov.ar/index.php/corpus/article/view/320/102 (Acceso: 4 de junio, 2018).

»Endere, M. L. (2013). Recaudos legales yéticos aplicables a los profesionales que trabajan con el patrimonio arqueológico y bioantropológico. En M. L. Endere, M. G. Chaparro y C. Mariano (Eds.), Temas de patrimonio cultural (pp. 13-34). Tandil: UNICEN.

"Endere, M. L. y Ayala, P. (2012). Normativa legal, recaudos éticos y práctica arqueológica. Un estudio comparativo de Argentina y Chile. Chungara. Revista de Antropología Chilena, $44(1), 39-58$.

»Endere, M. L. y Curtoni, R. (2006). Entre lonkos y "ólogos". La participación de la comunidad indígena Rankülche de Argentina en la investigación arqueológica. Arqueología Suramericana, 2(1), 72-92.

»Endere, M. L. y Rolandi, D. (2007). Legislación y gestión del patrimonio arqueológico. Breve reseña de lo acontecido en los últimos 70 años. Relaciones de la Sociedad Argentina de Antropología, XXXII, 33-54.

" García Guraieb, S., Bernal, V., González, P. N., Bosio, L. A. y Aguerre, A. M. (2009). Nuevos estudios del esqueleto del sitio Cerro Yanquenao (Colhue Huapi, Chubut): veintiocho años después. Magallania, 37(2), 165-175.

" García Guraieb, S., Bosio, L. A. y Pereyra, J. (2015). Treponematosis en Sudamérica prehispánica: revisión y actualización de casos y evidencias. Trabajo presentado en el VI Congreso de la Asociación de Paleopatología en Sudamérica. Buenos Aires, Argentina.

»Gómez Otero, J. (2011). La importancia de rescatar los enterratorios humanos en riesgo: experiencias en el nordeste de la provincia de Chubut. Cazadores-recolectores del Cono Sur, Revista de Arqueología, 5, 15-34.

» Gradín, C. J. (1989). Los grabados rupestres del Cerro Yanquenao en la Provincia de Chubut. En Carlos J. Gradín (Ed.), Grabados rupestres del Cerro Yanquenao en la Provincia de Chubut (pp.7-36). Chubut: Publicación del Pueblo del Chubut.

»Gradín, C. J. (2001). El arte rupestre de los cazadores de guanaco de Patagonia. En E. Berberián y A. E. Nielsen (Eds.), Historia Argentina Prehispánica (Tomo II, pp. 839-874). Córdoba: Brujas. 
» Guraieb, A. G. y Frère, M. M. (2012). Caminos y encrucijadas en la gestión del patrimonio arqueológico argentino. Buenos Aires: Facultad de Filosofía y Letras, Universidad de Buenos Aires.

» Lazzari, A. (Ed). (2011). Corpus. Archivos virtuales de la alteridad americana 1(1), http:// ppct.caicyt.gov.ar/index.php/corpus/issue/view/30/showToc (Acceso: 4 de Junio, 2018).

» Lazzari, A., Rodríguez, M. E. y Papazian, A. (2015). Juegos de visibilización, Antropología sociocultural de los pueblos indígenas en Pampa Patagonia. Papeles de trabajo, 9(16), 56-109.

» Organización Internacional del Trabajo (OIT). (1989). Convenio N. 169 sobre pueblos indígenas y tribales en países independientes. https://www.ilo.org/dyn/normlex/es/f?p=N ORMLEXPUB:12100:0::NO::P12100_ILO_CODE:C169 (acceso: 4 de julio, 2019).

»Política de restitución de restos humanos. (2018, julio). Restituciones. Museo de La Plata. Facultad de Ciencia Naturales y Museo. Recuperado de http://www.museo.fcnym. unlp.edu.ar/restituciones

»Pupio, A. y Salerno, V. (2014). El concepto de patrimonio en el campo de la Arqueología Argentina. Análisis de los trabajos presentados en los congresos nacionales de arqueología (1970-2010). Intersecciones en Antropología, 15, 115-129.

»Restituyeron los restos del hombre de cerro Yanquenao (2018, octubre). Diario Crónica, Comodoro Rivadavia. Recuperado de http://diariocronica.com.ar/530958-restituyeronlos-restos-del-hombre-de-cerro-yanquenao.html

» Rodríguez, M. E. (2011). “Casualidades y Causalidades" de los procesos de patrimonialización en la Provincia de Santa Cruz. En A. Lazzari (Ed.), Corpus. Archivos virtuales de la alteridad americana 1(1). http://ppct.caicyt.gov.ar/index.php/corpus/issue/ view/30/showToc (Acceso: 8 de febrero, 2019).

» Rodríguez, M.EyAlaniz, M. (2018). Política indígena participativa yetnografía colaborativa en la Provincia de Santa Cruz. En M. Carrasco (Ed.), Campos de interlocución y políticas del reconocimiento indígena en la Argentina (pp. 67-87). Buenos Aires: Antropofagia. 